\title{
Medicines use review service in community pharmacies in Spain: REVISA project
}

\section{Nuria García-Agua Soler ( $\nabla$ nuriags@uma.es )}

https://orcid.org/0000-0003-2979-5241

\section{Eugenia Gómez-Bermúdez}

Spanish Society of Family and Community Pharmacy

Vicente J. Baixauli-Fernández

Spanish Society of Family and Community Pharmacy

Sara Bellver-Beltrán

Spanish Society of Family and Community Pharmacy

Javier Velasco-Martínez

Spanish Society of Family and Community Pharmacy

Pablo Jiménez-Moreno

Spanish Society of Family and Community Pharmacy

María del Mar Arranz-Esteban

Spanish Society of Family and Community Pharmacy

Javier M. Romero-Sánchez

Spanish Society of Family and Community Pharmacy

Antonio J. García-Ruiz

University of Málaga

Francisco Jódar-Sánchez

Instituto de Biomedicina de Sevilla https://orcid.org/0000-0003-1092-9932

\section{Research article}

Keywords: Medicines use review; Community pharmacy; Adherence to medication; Polypharmacy; willingness to pay

Posted Date: September 12th, 2019

DOI: https://doi.org/10.21203/rs.2.14362/v1

License: (c) (i) This work is licensed under a Creative Commons Attribution 4.0 International License. Read Full License 


\section{Abstract}

Background: Community pharmacy services play an important role in controlling some factors related to medicine use, and pharmaceutical services integrated with primary healthcare services are critical to achieve the desired outcomes and to significantly reduce harms that can otherwise arise from multiple medicine use, such as non-adherence or medicine-related problems. The aim of the REVISA project is to carry out a study on preliminary implementation of the medicines use review (MUR) service in Spanish pharmacies through pharmacist-led initiatives to obtain a better understanding of patients' medication adherence and medicinerelated problems, together with satisfaction and acceptability of the service and whether patients might be willing to pay for it in the future.

Methods: A preliminary implementation, cross-sectional multicentre study was conducted using a convenience sample of voluntary community pharmacies from all regions of Spain. Descriptive and logistic regression analyses were undertaken.

Results: Sixty-four community pharmacies participated and a total of 495 patients were enrolled. A slight predominance of women $(56 \%)$ was noted, with a mean age of $66.09 \pm 14.71$ years and a mean consumption of $5.68 \pm 2.97$ medicines. As results of MUR, a total 550 referrals were made. Non-adherence with the medication $(\mathrm{OR}=1.74 ; 95 \% \mathrm{Cl}: 1.17$ to 2.58$)$, polypharmacy $(\mathrm{OR}=1.50 ; 95 \% \mathrm{Cl}$ : 1.02 to 2.20$)$ and help with medication ( $\mathrm{OR}=3.03 ; 95 \% \mathrm{Cl}: 1.45$ to 6.34$)$ were associated with referrals. Patients were adherent for $68.3 \%$ of their medicines. However, at the patient level, only $31.5 \%$ were adherent. Polypharmacy patients older than 65 years increased the risk of non-adherence ( $\mathrm{OR}=1.56 ; 95 \% \mathrm{Cl}: 1.06$ to 2.30$)$. The mean time employed by the pharmacists in the MUR was $52.80 \pm 31.52$ minutes (MUR-related cost of $€ 17.27$ ). Most patients expressed a high level of satisfaction with the MUR service (98.5\%) and a willingness to pay for it (84\%).

Conclusions: The MUR service in community pharmacies in Spain can be delivered, that it appears to be acceptable to patients and that most patients said they would be willing to pay for it. Pharmacists self-reported the length of time taken to deliver a MUR although the feasibility of incorporating into everyday practice would need to be assessed.

\section{Background}

The ageing population, less healthy lifestyles and an increasing incidence of chronic conditions mean that multimorbidity is on the rise [1]. Major consequences of multimorbidity are functional impairment, poor quality of life, risk of mortality and high healthcare utilization and costs [2-4]. In addition, patients with multimorbidity are at higher risk of safety issues for many reasons, including polypharmacy, which may lead to poor medication adherence and adverse drug events [5-8].

Community pharmacy services play an important role in controlling some factors related to medicine use [9-12], and pharmaceutical services integrated with primary healthcare services are critical to achieve the desired outcomes and to significantly reduce harms that can otherwise arise from multiple medicine use, such as non-adherence or medicine-related problems [13].

Spain is among the European countries experiencing a major change toward an older population structure [14]. The intensity of the ageing process of the resident population in Spain is set to rise. In 2052, the group aged 64 years and over will account for $37 \%$ of the total population of Spain [15].

The Spanish community pharmacy is considered as a private healthcare facility with a public interest [16]. The head of the community pharmacy has to be a pharmacist and each pharmacist can only be the owner of one single community pharmacy. A homogenous distribution of pharmacies has been achieved, with the average ratio of inhabitants to pharmacies among the lowest in Europe (2,186 inhabitants/pharmacy) [17]. Hence, $87 \%$ of the Spanish population has a pharmacy less than 250 meters from their homes, which implies that patients are regular customers and can benefit from services to improve the adherence and knowledge of their medications.

During the last years, the Spanish community pharmacies have evolved in their approach to the patient, actively engaging in the services they provide. The Spanish Society of Family and Community Pharmacy (SEFAC, Sociedad Española de Farmacia Familiar y Comunitaria) and the General Pharmaceutical Council of Spain (Consejo General de Colegios Oficiales de Farmacéuticos) have been developing strategies that allow the introduction of a new model of professional practice, based on a greater commitment and multidisciplinary cooperation, for the benefit of the patient $[17,18]$. 
The aim of the REVISA project is to carry out a study on preliminary implementation of the medicines use review (MUR) service in Spanish pharmacies through pharmacist-led initiatives to obtain a better understanding of patients' medication adherence and medicine-related problems, together with satisfaction and acceptability of the service and whether patients might be willing to pay for it in the future.

\section{Methods}

\section{Study design}

A preliminary implementation, cross-sectional multicentre study was conducted using a convenience sample of voluntary community pharmacies from all regions of Spain.

The study subjects were patients older than 18 years who signed informed consent and belonged to one of the following groups: i) they were users of complex medicines [19]; ii) they were users of high-risk medicines [20]; iii) and they were polypharmacy patients (patients with five or more prescribed medicines). The following groups were excluded from the study: i) pregnant or lactating women; ii) individuals undergoing treatment with chemotherapy or radiotherapy; iii) individuals with physical or mental disabilities; iv) individuals who had undergone a medication review in the past year; and v) individuals whose medication was subject to a delay in pick-up from the community pharmacy by their caregivers or family members.

\section{REVISA Project}

The REVISA project managed by Subcommittee MUR of SEFAC consisted in the developed of an intervention protocol based on the official guidance of MUR service by the National Health Service. The MUR in England involves the pharmacist reviewing the patient's use of their medication, ensuring they understand how their medicines should be used and why they have been prescribed, identifying any problems and then, where necessary, providing feedback to the prescriber [21].

Our preliminary implementation study was developed in two phases: i) the enrolment of community pharmacists who voluntarily and selflessly (there was no payment or other incentive) participated and trained in the MUR service between October 2015 and March 2016. The training consisted of theoretical and practical online sessions and in-person, hands-on sessions. Community pharmacists who successfully passed (approved the exam and the clinical cases) this phase could start phase two; ii) the enrolment of a minimum of 8 patients in community pharmacies and provision of the MUR service between March and July 2016. The MUR service was provided at a single visit without patient follow-up.

\section{Variables}

The characteristics of the community pharmacies (region, type of pharmacy), patients (gender, age, marital status, education level, employment status, cohabitation, number of medicines prescribed, need for help with medicines and country of origin) and medicines (classified using the Anatomical, Therapeutic, Chemical (ATC) Classification system) were assessed. The main outcome variables were as follows:

\section{Medicine use evaluation}

Evaluation includes two processes, based on the official guidance of MUR service by the National Health Service [21]: i) assessing medicine use and ii) providing information/suggestions to the patients regarding the use of medicines and making referrals to other health professionals or professional pharmaceutical services (see questionnaire in Additional file 1).

The pharmacists used the following questions to assess the use of each medicine:

-How are you managing with your medicines? Is there anything you are worried about?

-How do you take/use your medication? The pharmacist will check whether the patient is taking the medicine as prescribed in terms of dose, pattern, and duration. Is the medication taken before or after eating? Are the tablets split? Are the medications prepared/administered correctly? The pharmacist will check for the presence of conservation/disposal.

-Do you have any problems with your medicines or concerns about taking/using them? (Difficulty with and concerns about use).

Page 3/14 
-Do you know why you are taking this medicine?

-Do you think this medicine is causing any adverse or unexpected effects?

-Is there anything else you would like to know about your medication?

-Identified incidents may include duplicity, contraindication, interactions or others.

In the second part of the process, the following information was provided:

-Tailored information about the medication.

-Basic information about healthy routines: vaccination, healthy lifestyle (diet and exercise), illness.

-Support and advice to improve the use of the medication.

-Referrals to general practitioners (GPs) (indicate the medicine related to the referral) and other healthcare professionals (indicate the number of medicines related to the referral and the professional being consulted).

-Referrals to other services in the community pharmacy: pharmaceutical care service with follow-up, smoking cessation, personalized medication dosage systems, blood pressure monitoring, nutritional status assessment and health education.

-Notifications using the "yellow card" system of the Spanish Pharmacovigilance System for Medicinal Products for Human Use [22].

\section{Adherence}

Adherence was measured using the Morisky-Green test [23]. This test was administered to each patient for each of the prescribed medications. The variable was categorized as adherent or non-adherent; patients were considered non-adherent when they were non-adherent to any one of their medications.

\section{MUR-related time and cost}

The time devoted to interviews with patients and registering the MUR form and reports were considered as the time associated with the MUR service. The unit cost of the community pharmacist was calculated taking into account the pharmacist' salary in the Spanish community pharmacy agreement [24], and on the time the pharmacist devoted to the MUR service.

\section{Health-related quality of life}

Health-related quality of life was measured using the Spanish version of the EuroQol-5D-5L [25]. This generic questionnaire describes the health status along five dimensions (mobility, personal care, usual activities, pain/discomfort and anxiety/depression) and contains a visual analogue scale (VAS).

\section{Satisfaction and willingness to pay}

To evaluate satisfaction with the MUR service, a validated satisfaction questionnaire was used to evaluate the pharmaceutical care service provided in community pharmacies [26]. To determine the patient's willingness to pay, they were asked whether they would use the MUR service again and, if so, the amount they would be willing to pay for it. The response options were structured in closed ranges from 0 euros to more than 30 euros. Both questionnaires were anonymous.

\section{Statistical analysis}

A descriptive analysis was performed using frequencies and percentages for qualitative data and means \pm standard deviation for quantitative data. Comparisons between variables were performed using bivariate analysis. Qualitative data were obtained using the chi-squared test or Fisher's exact test, depending on the study group in question. The methods used to compare quantitative data depended on various assumptions and included parametric techniques (T-test) and nonparametric techniques (Mann-Whitney U-test). The relationship between quantitative variables was analysed through Pearson's correlation coefficient. The estimate of the 
magnitude of the relationship between variables was analysed using the odds ratio (OR) and $95 \%$ confidence interval $(95 \% \mathrm{Cl})$ by a logistic regression analysis. The data were analysed using the SPSS 20.0 statistical program.

\section{Results}

\section{Community pharmacies and patients}

Sixty-four community pharmacies participated, most of them were suburban pharmacies (59.4\%), followed by rural (20.3\%), transit (17.2\%) and coastal (3.1\%) pharmacies. A total of 495 patients were enrolled. Table 1 shows the sociodemographic characteristics of the participating patients. A slight predominance of women (56\%) was noted, with a mean age of $66.09 \pm 14.71$ years and a mean consumption of $5.68 \pm 2.97$ medicines. More than half of the patients were married $(62.6 \%)$, most were retired (53.9\%), and most were highly educated ( $81.4 \%$ ). Additionally, $62.2 \%$ of the patients were aged 65 years or older, and $61.2 \%$ were polypharmacy patients, but only $45.3 \%$ of patients met both conditions.

Table 1 Patient sociodemographic characteristics 


\begin{tabular}{|c|c|c|}
\hline Variable & Categories & Value \\
\hline Gender & $\begin{array}{l}\text { Female } \\
\text { Male }\end{array}$ & $\begin{array}{l}279(56.4) \\
216(43.6)\end{array}$ \\
\hline Age in years & $\begin{array}{l}\text { Mean + SD } \\
<65 \\
\geq 65\end{array}$ & $\begin{array}{l}66.1 \pm 14.7 \\
187(37.8) \\
308(62.2)\end{array}$ \\
\hline Marital status ${ }^{a}$ & $\begin{array}{l}\text { Single } \\
\text { Married } \\
\text { Separated/divorced } \\
\text { Widow }\end{array}$ & $\begin{array}{l}50(10.1) \\
310(62.6) \\
37(7.5) \\
94(19)\end{array}$ \\
\hline Education level $^{a}$ & $\begin{array}{l}\text { None } \\
\text { Elementary } \\
\text { Secondary } \\
\text { University } \\
\text { Other }\end{array}$ & $\begin{array}{l}92(18.6) \\
183(37) \\
104(21) \\
102(20.6) \\
3(0.6)\end{array}$ \\
\hline Occupation $^{\mathrm{a}}$ & $\begin{array}{l}\text { Employed } \\
\text { Unemployed } \\
\text { Retired } \\
\text { Homemaker } \\
\text { Other }\end{array}$ & $\begin{array}{l}91(18.4) \\
31(6.3) \\
267(53.9) \\
67(13.5) \\
14(2.8)\end{array}$ \\
\hline Cohabitation $^{\mathrm{b}}$ & $\begin{array}{l}\text { Alone } \\
\text { Partnered } \\
\text { Children } \\
\text { Caregiver - part-time } \\
\text { Caregiver - full-time } \\
\text { Other }\end{array}$ & $\begin{array}{l}81(16.4) \\
273(55.2) \\
99(20) \\
13(2.6) \\
7(1.4) \\
30(6.1)\end{array}$ \\
\hline Number of medicines prescribed & $\begin{array}{l}\text { Mean + SD } \\
\leq 4 \\
5-9 \\
10-14 \\
\geq 15\end{array}$ & $\begin{array}{l}5.68 \pm 2.97 \\
192(38.8) \\
250(50.5) \\
46(9.3) \\
7(1.4)\end{array}$ \\
\hline
\end{tabular}




\begin{tabular}{|l|l|l|} 
Help with medicationa $^{\text {a }}$ & None & $397(80.2)$ \\
& Children & $25(5.1)$ \\
& Caregiver & $13(2.6)$ \\
& Others & $20(4.0)$ \\
\hline Country of origin $^{\text {a }}$ & Spain & $481(97.2)$ \\
& Other & $12(2.4)$ \\
\hline
\end{tabular}

Notes: Data are expressed as $\mathrm{n}(\%)$ or mean $\pm \mathrm{SD} ;{ }^{\mathrm{a}}$ There are missing values for these variables; ${ }^{\mathrm{b}}$ Answers were not mutually exclusive. SD: Standard deviation.

In total, 2,811 medicines were reviewed, over $90 \%$ were from the following six groups of the first ATC classification system (anatomical level): A. Alimentary tract and metabolism: 495 medicines (17.6\%); B. Blood and blood-forming organs: 230 medicines (8.2\%); C. Cardiovascular system: 900 medicines (32\%); M. Musculo-skeletal system: 157 medicines (5.6\%); N. Nervous system: 566 medicines (20.1\%); R. Respiratory system: 210 medicines (7.5\%).

\section{Medicine use evaluation}

Before starting the MUR service, the pharmacist asked patients the following: "How are you managing with your medicines? Is there anything you are worried about?". For 2,541 medicines (90.4\%), the patients reported that they were doing well.

Table 2 shows the medicine use evaluation. Notably, an inappropriate pattern was observed for $11.6 \%$ of the medicines evaluated, suboptimal administration was noted in $7.2 \%$ of cases, and a lack of knowledge of the indication for the medicine was found in $10.3 \%$ of cases. The pharmacists detected suspected adverse drug reactions for $8.8 \%$, interactions for $4.4 \%$, duplicity for $1.6 \%$ and contraindications for $0.7 \%$.

Table 2 Medicine use evaluation 


\begin{tabular}{|l|r|r|r|}
\hline & Yes & No & DK \\
\hline Inappropriate dose & $146(5.2)$ & $2,617(93.1)$ & $48(1.7)$ \\
\hline Inappropriate pattern & $325(11.6)$ & $2,445(87.0)$ & $41(1.4)$ \\
\hline Inappropriate duration & $125(4.5)$ & $2,643(94.0)$ & $43(1.5)$ \\
\hline Suboptimal administration & $203(7.2)$ & $2,563(91.2)$ & $45(1.6)$ \\
\hline Inappropriate conservation & $115(4.1)$ & $2,640(93.9)$ & $56(2.0)$ \\
\hline Inappropriate disposal & $273(9.7)$ & $2,415(85.9)$ & $123(4.4)$ \\
\hline Difficulty with use & $110(3.9)$ & $2,651(94.3)$ & $50(1.8)$ \\
\hline Concerns about use & $193(6.9)$ & $2,548(90.6)$ & $70(2.5)$ \\
\hline Patient does not know the drug indication & $289(10.3)$ & $2,446(87.0)$ & $76(2.7)$ \\
\hline Suboptimal treatment of illness & $170(6.1)$ & $2,550(90.7)$ & $91(3.2)$ \\
\hline Inappropriate dose or duration (deliberate) & $179(6.4)$ & $2,447(87.0)$ & $185(6.6)$ \\
\hline Suspected adverse drug reactions & $246(8.8)$ & $2,516(89.5)$ & $49(1.7)$ \\
\hline Patient requests further information & $176(6.3)$ & $2,584(91.9)$ & $51(1.8)$ \\
\hline Duplicity & $44(1.6)$ & $2688(95.6)$ & $79(2.8)$ \\
\hline Contraindication & $20(0.7)$ & $2714(96.6)$ & $77(2.7)$ \\
\hline Interactions & $124(4.4)$ & $2601(92.5)$ & $86(3.1)$ \\
\hline Other & $116(4.1)$ & $2492(88.7)$ & $203(7.2)$ \\
\hline
\end{tabular}

Data are expressed as n (\%). DK: Don't know.

The pharmacists provided tailored information for 2,073 medicines (73.8\%) and 1,316 suggestions for improving use (46.8\%). At the patient level, the pharmacists provided personalized information to 473 patients (95.6\%), suggestions for improvement to 423 patients (85.5\%) and basic health education information (vaccinations, healthy lifestyle-diet and exercise, etc.) to 417 patients (84.2\%).

As results of MUR, a total 550 referrals were made in 334 patients: 164 (29.8\%) to Primary Care, 19 (3.5\%) to Specialized Care and the remaining referrals were to professional pharmaceutical services: $154(28 \%)$ to the blood pressure monitoring service; 56 $(10.2 \%)$ to the nutritional status assessment service; $55(10 \%)$ to the personalized medication dosage systems service; 42 (7.6\%) to the pharmaceutical care service with follow-up; 31 (5.6\%) to the smoking cessation service; and $29(5.3 \%)$ to other pharmaceutical services. Fourteen drug notifications were also made using the "yellow card" system.

Non-adherence with the medication, polypharmacy and help with medication were the main factors associated with referrals (Table $3)$.

\section{Table 3 Predictors of referrals}




\begin{tabular}{|l|rr|rr|}
\hline Factor & OR $(95 \%$ Cl $)$ & P value & Between-group difference P value \\
\hline All referrals & & & \\
Non-adherence & $1.74(1.17$ to 2.58$)$ & 0.006 & $0.39(0.19$ to 0.58$)$ & $<0.001$ \\
Polypharmacy & $1.50(1.02$ to 2.20$)$ & 0.038 & $0.25(0.06$ to 0.44$)$ & 0.01 \\
Help with medication & $3.03(1.45$ to 6.34$)$ & 0.003 & $0.62(0.35$ to 0.89$)$ & $<0.001$ \\
\hline Primary Care and Specialized Care & & & & \\
Non-adherence & $1.80(1.18$ to 2.75$)$ & 0.006 & $0.13(0.04$ to 0.22$)$ & 0.01 \\
Polypharmacy & $1.59(1.07$ to 2.34$)$ & 0.021 & $0.10(0.02$ to 0.19$)$ & 0.02 \\
Help with medication & $2.05(1.20$ to 3.53$)$ & 0.009 & $0.17(0.05$ to 0.30$)$ & 0.008 \\
\hline Pharmaceutical services & $1.36(0.93$ to 1.99$)$ & 0.11 & $0.08(-0.02$ to 0.17$)$ & 0.11 \\
Non-adherence & $1.47(1.02$ to 2.11$)$ & 0.038 & $0.10(0.01$ to 0.19$)$ & 0.038 \\
Polypharmacy & $3.12(1.69$ to 5.76$)$ & $<0.001$ & $0.26(0.13$ to 0.39$)$ & $<0.001$ \\
\hline
\end{tabular}

\section{Adherence}

Adherence for the 2,811 medicines was analysed. Some patients claimed they had never forgotten to take their medication (80.6\%), took it at the right times (88.4\%) and did not stop taking it even if they felt well (87.2\%) or felt ill (93.4\%). Therefore, the patients were adherent for $68.3 \%$ of their medicines. Differences were found in the degree of adherence based on the group in the first level of the ATC classification system: A (72.4\%); B: (80.3\%); C: (74.3\%); M: (60\%); N: (65\%); R: (64.3\%); for the drugs in other groups: $73.8 \%(p<0.001)$.

However, the results varied at the patient level and only 156 patients (31.5\%) were adherent. Polypharmacy was associated with non-adherence. Percentages of non-adherence were $71.0 \%$ and $64.6 \%$ among polypharmacy and non-polypharmacy patients respectively ( $\mathrm{OR}=1.34 ; 95 \% \mathrm{Cl}$ : 0.91 to 1.97). Likewise, among polypharmacy patients older than 65 years, the degree of nonadherence was higher $(73.7 \%)$ than that of the remaining patients $(64.2 \%)(\mathrm{OR}=1.56 ; 95 \% \mathrm{Cl}: 1.06$ to 2.30$)$.

\section{MUR-related time and costs}

The mean time employed by the pharmacists in the MUR was $52.80 \pm 31.52$ minutes: $27.34 \pm 15.15$ in the interview and $25.39 \pm 21.32$ for registering the MUR forms and reports.

There was a significant correlation between the MUR time and number of medicines $(r=0.54 ; p<0.001)$. MUR time increased significantly for polypharmacy patients $(62.27 \pm 33.92$ vs $37.98 \pm 19.77 ; p<0.001)$, patients aged 65 years or older $(55.57 \pm 32.95$ vs $48.17 \pm 28.48 ; p=0.013)$ and non-adherent patients ( $54.94 \pm 33.29$ vs $48.17 \pm 26.84 ; p=0.029)$.

The mean costs associated with the time the pharmacists spent on each patient interview and MUR form registration were $€ 8.98 \pm$ $€ 4.99$ and $€ 8.29 \pm € 7.01$, respectively, resulting in a mean MUR service cost of $€ 17.27 \pm 10.31$.

\section{Health-related quality of life}

At least half of the patients reported having no health problems on most of the dimensions: $58.4 \%$ for mobility, $77.0 \%$ for personal care, $68.7 \%$ for usual activities, $38.6 \%$ for pain/discomfort and $56.2 \%$ for anxiety/depression. 
The mean VAS score was $66.06 \pm 17.81$. Quality of life reduced significantly for polypharmacy $(63.39 \pm 17.72$ vs $70.25 \pm 17.17$; $p<0.001)$, age older than 65 years $(64.59 \pm 17.53$ vs $68.57 \pm 18.06 ; p=0.02)$ and help with medication $(57.12 \pm 16.86$ vs $66.97 \pm 17.66$; $p<0.001)$. No differences were detected according non- adherence with the medication $(65.62 \pm 17.48$ vs $67.01 \pm 18.53 ; p=0.45)$.

\section{Satisfaction and willingness to pay}

$98.5 \%$ of patients expressed a high level of satisfaction with the MUR service $(68.9 \%$ and $29.5 \%$ of patients were very satisfied and satisfied respectively). Among the main benefits of the MUR service that patients highlighted were better understanding of the medicines used (97.2\%), effective resolution of health problem(s) $(93.6 \%)$, learning the need to comply with the prescribed treatment $(91.0 \%)$, learning the undesirable effects of the drugs used $(87.7 \%)$, and reducing the undesirable effects of the drugs used (83.6\%).

Prior to estimating their willingness to pay for the MUR service, the patients were asked whether they would use this service again and if they would recommend the service to a friend or family member. Very similar percentages were obtained for both questions: $90.7 \%$ and $91.1 \%$ respectively. Additionally, $90.7 \%$ of patients indicated that they would likely use the service again, $8.4 \%$ of patients were undecided, and only $0.9 \%$ stated that they were unlikely to use the service again. Moreover, $90.5 \%$ of patients would recommend the service without hesitation, $7.8 \%$ would recommend it with reservations, and only $1.1 \%$ would not recommend it.

Four hundred nineteen patients expressed interest in receiving the MUR service. The willingness to pay was: 17 patients (4.1\%) more than $30 € ; 35$ patients (8.4\%) between $21 €-30 €$; 91 patients (21.7\%) between $11 €-20 € ; 113$ patients (27.0\%) between $6 €-10 €, 96$ patients $(22.9 \%)$ until $5 €, 61$ patients $(14.6 \%)$ were not willing to pay anything for it and 6 patients $(1.4 \%)$ don't know.

\section{Discussion}

Our study presents initial findings on a preliminary implementation of the MUR service through pharmacist-led initiatives to obtain a better understanding of patients' medication adherence and medicine-related problems, together with satisfaction and acceptability of the service and whether patients might be willing to pay for it in the future.

The results of this study suggest that patients can obtain extra help with their medications through the MUR service. Non-adherence and poor knowledge about medicines are behaviours that intensify with age and polypharmacy, indicating the target population for which MUR can be most effective [27-32].

The REVISA project has proven useful for patients given the high number of interventions that have occurred, which provided personalized information about medicines, suggestions regarding their use, health education and referrals to various health professionals, in particular GPs. MUR service may offer an opportunity to promote inter-professional collaboration between pharmacists and physicians. However, it has been reported that some of the problems with MUR have been that they do not integrate well with the patients' primary care pathway, and that physicians s are commonly not particularly positive about this service [33-36]. In addition, a lack of communication and collaboration between GPs and community pharmacists can have an impact on the relationship between the patients and their GPs [37, 38].

Our results show that the MUR service appears well received by patients, even if an additional cost would be involved for the individual patient. Patients reported a high degree of satisfaction with the MUR service, in accordance with previous studies [37, 39, 40]. However, evidence that patients do not necessarily see a role of community pharmacy in delivering services that go much beyond their traditional supply and related advice function is also available [41].

The feasibility of incorporating this service into everyday practice would need to be assessed. Few studies have assessed the time invested in this service, which is an important factor considering the cost involved. Lee et al. [42] obtained a median time required for pharmacists to perform the initial MUR visit very similar to our results. Our results show that there was a significant correlation between the MUR time and number of medicines. Polypharmacy, age and non-adherence were other factors that significantly increased the MUR time.

There were some limitations to the present study. Non-random selection of study community pharmacies and patients limits generalizability of the results, although the participating community pharmacies represented all regions of Spain. A high degree of

Page 10/14 
satisfaction with the services was obtained. However, it should be kept in mind that patient satisfaction with community pharmacy services, which they have agreed to participate in, is usually high. Finally, the effectiveness of the referrals to health professionals is unclear, since there was no follow-up. Continuation of the REVISA study would be necessary to accurately assess any benefits of MUR service.

\section{Conclusion}

The MUR service in community pharmacies in Spain can be delivered, that it appears to be acceptable to patients and that most patients said they would be willing to pay for it. Pharmacists self-reported the length of time taken to deliver a MUR although the feasibility of incorporating into everyday practice would need to be assessed.

\section{List Of Abbreviations}

95\% Cl: 95\% Confidence interval.

ATC: Anatomical, Therapeutic, Chemical.

DK: Don't know.

GPS: General practitioners.

MUR: Medicines use review.

OR: Odds ratio.

SEFAC: Spanish Society of Family and Community Pharmacy.

SD: Standard deviation.

VAS: Visual analogue scale.

\section{Declarations}

\section{Ethics approval and consent to participate}

The protocol, and participant information and consent document were submitted to the Málaga Regional Research Ethics Committee, who approved the study. All patients signed an informed consent before their enrolment in the study.

\section{Consent for publication}

Written consent for publishing the results was obtained from patients before their enrolment in the study.

\section{Availability of data and materials}

The data that support the findings of this study are available from The Spanish Society of Family and Community Pharmacy (SEFAC) but restrictions apply to the availability of these data, which were used under license for the current study, and so are not publicly available. Data are however available from the authors upon reasonable request and with permission of SEFAC.

\section{Competing interests}

The authors declare that they have no competing interests.

\section{Funding}

The REVISA project presents independent research funded by The Spanish Society of Family and Community Pharmacy (SEFAC). 
Nuria García-Agua Soler (NGS), Vicente J. Baixauli-Fernández (VJB), Sara Bellver-Beltrán (SB), Javier Velasco-Martínez (JV), Pablo Jiménez-Moreno (PJ), María del Mar Arranz-Esteban (MMA) and Javier M. Romero-Sánchez (JMR) conceptualized the study.

Eugenia Gómez-Bermúdez (EG)

VJB, SB, JV, PJ, MMA and JMR developed the MUR protocol, participated in the MUR training, monitored the recruitment process and carried out data collection. NGS, EG, Antonio J. García-Ruiz (AJG) and Francisco Jódar-Sánchez (FJ) designed the study, carried out the analyses, critically reviewed the results of analyses, and reviewed and revised the manuscript. NGS drafted the initial manuscript. All authors approved the final manuscript as submitted.

\section{Acknowledgements}

The authors are grateful to the Spanish pharmacists and patients who have been involved in this study.

\section{Results}

1. Multimorbidity: Technical Series on Safer Primary Care. Geneva: World Health Organization; 2016. Licence: CC BY-NC-SA 3.0 IGO.

2. Marengoni A, Angleman S, Melis R, et al. Aging with multimorbidity: a systematic review of the literature. Ageing Res Rev. 2011;10:430-439.

3. Bähler C, Huber CA, Brüngger B, Reich O. Multimorbidity, health care utilization and costs in an elderlycommunity-dwelling population: a claims data based observational study. BMC Health Serv Res. 2015;15:23.

4. Wolff JL, Starfield B, Anderson G. Prevalence, expenditures, and complications of multiple chronic conditions in the elderly. Arch Intern Med. 2002;162:2269-2276.

5. Panagioti M, Stokes J, Esmail A, et al. Multimorbidity and Patient Safety Incidents in Primary Care: A Systematic Review and Meta-Analysis. PLoS One. 2015;28:e0135947.

6. Calderón-Larrañaga A, Poblador-Plou B, González-Rubio F, Gimeno-Feliu LA, Abad-Díez JM, Prados-Torres A. Multimorbidity, polypharmacy, referrals, and adverse drug events: are we doing things well? Br J Gen Pract.2012;62:e821-6.

7. Phillips RL Jr, Bartholomew LA, Dovey SM, Fryer GE Jr, Miyoshi TJ, Green LA. Learning from malpractice claims about negligent, adverse events in primary care in the United States. Qual Saf Health Care. 2004;13:121-126.

8. Mannucci PM, Nobili A, Pasina L, REPOSI Collaborators (REPOSI is the acronym of REgistro POliterapie SIMI, Società Italiana di Medicina Interna). Polypharmacy in older people: lessons from 10 years of experience with the REPOSI register. Intern Emerg Med. 2018;13:1191-1200.

9. Soler O, Barreto JOM. Community-Level Pharmaceutical Interventions to Reduce the Risks of Polypharmacy in the Elderly: Overview of Systematic Reviews and Economic Evaluations. Front Pharmacol. 2019;10:302.

10. Jokanovic N, Tan EC, Sudhakaran S, Kirkpatrick CM, Dooley MJ, Ryan-Atwood TE. Pharmacist-led medication review in community settings: An overview of systematic reviews. Res Social Adm Pharm. 2017;13:661-685.

11. Yuan C, Ding Y, Zhou K, Huang Y, Xi X. Clinical outcomes of community pharmacy services: A systematic review and metaanalysis. Health Soc Care Community. 2019.

12. Jódar-Sánchez F, Malet-Larrea A, Martín JJ, et al. Cost-utility analysis of a medication review with follow-up service for older adults with polypharmacy in community pharmacies in Spain: the conSIGUE program. Pharmaeconomics. 2015;33:599-610.

13. Roughead EE, Vitry Al, Caughey GE, Gilbert AL. Multimorbidity, care complexity and prescribing for the elderly. Aging Health. 2011;7:695-705.

14. Serrano JP, Latorre JM, Gatz M. Spain: promoting the welfare of older adults in the context of population aging. Gerontologist. 2014;54:733-740.

15. National Statistics Institute. Population and demographic phenomena projected.

http://www.ine.es/dyngs/INEbase/en/operacion.htm?

C=Estadistica_C\&cid=1254736176953\&menu=ultiDatos\&idp=1254735572981. Accessed 20 May 2019.

16. Law 16/1997, 25th April, on the Regulation of Community Pharmacy Services. BOE-A-1997-9022. Pages $13450-13452$.

Page $12 / 14$ 
17. Spanish Society of Family and Community Pharmacy. Available from: https://www.campussefac.org/programas-capacitacion. Accessed 20 May 2019.

18. General Pharmaceutical Council of Spain. https://www.portalfarma.com/Profesionales/organizacionfcolegial/profesionfarma/Paginas/colegiaciondatestadisticos.aspx. Accessed 20 May 2019.

19. García de Bikuña Landa B. Complex medicines. 4st ed. Editorial: Pharmaceutical Training Center LS; 2017.

20. Institute for safe medication practices. High-risk medicines. 2015. http://www.ismp-espana.org/documentos/view/39. Accessed 7 July 2019.

21. Pharmaceutical Services Negotiating Committee. https://psnc.org.uk/services-commissioning/advanced-services/murs/mursthe-basics/. Accessed 7 July 2019.

22. Reporting of suspected adverse drug reactions by healthcare professionals Spanish Agency of Medicines and Medical Devices. 2013. https://www.aemps.gob.es/informa/notasInformativas/medicamentosUsoHumano/seguridad/2013/NI-MUH_FV_022013-notifica-ram.htm. Accessed 7 July 2019.

23. Morisky DE, Green LW, Levine DM. Concurrent and predictive validity of a self-reported measure of medication adherence. Med Care. 1986;24:67-74.

24. Resolución de 9 de abril de 2014, de la Dirección General de Empleo, por la que se registra y publica el laudo arbitral para oficinas de farmacia. (BOE, núm. 112, de 8 de mayo de 2014). https://www.boe.es/diario_boe/txt.php?id=BOE-A-2014-4846. Accessed 7 July 2019.

25. Hernandez G, Garin 0, Pardo Y, et al. Validity of the EQ-5D-5L and reference norms for the Spanish population. Qual Life Res. 2018;27:2337-2348.

26. Armando PD, Martínez Pérez SR, Molina Guerra AC, Martí Pallarés M, Solá Uthurry NH, Faus Dáder MJ. Development and validation of a patient satisfaction questionnaire on pharmaceutical care in community pharmacies. Rev Calid Asist. 2012;27:311-318.

27. Kharjul M, Braund R, Green J. The influence of pharmacist-led adherence support on glycaemic control in people with type 2 diabetes. Int J Clin Pharm. 2018;40:354-359.

28. Messerli M, Vriends N, Hersberger KE. Humanistic outcomes and patient acceptance of the pharmacist-led medication review "Polymedication Check" in primary care in Switzerland: a prospective randomized controlled trial. Patient Prefer Adherence. 2018;19:1071-1078.

29. Manfrin A, Tinelli M, Thomas T, Krska J. A cluster randomised control trial to evaluate the effectiveness and cost-effectiveness of the Italian medicines use review (I-MUR) for asthma patients. BMC Health Serv Res. 2017;17:300.

30. Messerli M, Blozik E, Vriends N, Hersberger KE. Impact of a community pharmacist-led medication review on medicines use in patients on polypharmacy-a prospective randomised controlled trial. BMC Health Serv Res. 2016;16:145.

31. Hatah E, Tordoff J, Duffull SB, Cameron C, Braund R. Retrospective examination of selected outcomes of Medicines Use Review (MUR) services in New Zealand. Int J Clin Pharm. 2014;36:503-512.

32. Okuyan B, Sancar M, Izzettin FV. Assessment of medication knowledge and adherence among patients under oral chronic medication treatment in community pharmacy settings. Pharmacoepidemiol Drug Saf. 2013;22:209-214.

33. Cardwell K, Hughes CM, Ryan C. Community pharmacists' views of using a screening tool to structure medicines use reviews for older people: findings from qualitative interviews. Int J Clin Pharm. 2018;40:1086-1095.

34. Jacobs S, Bradley F, Elvey R, et al. Investigating the organisational factors associated with variation in clinical productivity in community pharmacies: a mixed-methods study. Southampton (UK): NIHR Journals Library; 2017. Health Services and Delivery Research.

35. Bardet JD, Vo TH, Bedouch P, Allenet B. Physicians' and community pharmacists' collaboration in primary care: a review of specific models. Res Soc Adm Pharm. 2015;11:602-622.

36. Jové AM, Fernández A, Hughes C, Guillén-Solà M, Rovira M, Rubio-Valera M. Perceptions of collaboration between general practitioners and community pharmacists: findings from a qualitative study based in Spain. J Interprof Care. 2014;28:352-357.

37. Latif A, Pollock K, Boardman HF. Medicines use reviews: a potential resource or lost opportunity for general practice? BMC Fam Pract. 2013;14:57. 
38. McDonald R, Cheraghi-Sohi S, Sanders C, Ashcroft D. Professional status in a changing world: The case of medicines use reviews in English community pharmacy. Soc Sci Med. 2010;71:451-458.

39. Hindi A, Parkhurst C, Rashidi Y, Ho SY, Patel N, Donyai P. Development and utilization of the Medicines Use Review patient satisfaction questionnaire. Patient Prefer Adherence. 2017;20:1797-1806.

40. Latif A, Boardman HF, Pollock K. Understanding the patient perspective of the English community pharmacy Medicines Use Review (MUR). Res Social Adm Pharm. 2013;9:949-957.

41. Hindi AMK, Schafheutle El, Jacobs S. Patient and public perspectives of community pharmacies in the United Kingdom: A systematic review. Health Expect. 2018;21:409-428.

42. Lee E, Braund R, Tordoff J. Examining the first year of Medicines Use Review services provided by pharmacists in New Zealand: 2008. N Z Med J. 2009;122:3566.

\section{Supplementary Files}

This is a list of supplementary files associated with this preprint. Click to download.

- Additionalfile1.pdf 